\title{
Caring Senior: A Brazilian health model with emphasis at light care levels
}

Renato Veras ${ }^{1}$

\section{Abstract}

The present article discusses the creation of an elderly care model entitled Caring Senior. Population aging caused by demographic and epidemiological changes in Brazil, a relatively recent phenomenon, requires an efficient response. Based on a critical analysis of healthcare models for the elderly, the text presents a proposal for the healthcare of this age group, with emphasis on low intensity levels of care, focusing on health promotion and prevention, in order to avoid overload in the system. Integrated care models aim to solve the problem of fragmented and poorly coordinated care in current health systems. The more health professionals know about the history of their patients, the better the results. This is how the contemporary and resolutive models of care recommended by HealthCare. most major national and international health agencies should function. A higher quality, more resolutive and cost-effective care model is the focus of the present study. 


\section{INTRODUCTION}

One of mankind's greatest achievements has been the extension of life expectancy, accompanied by a substantial improvement in the health parameters of populations, despite the fact that these achievements are far from equitably distributed across countries and socioeconomic contexts. Reaching old age, which was once the privilege of a few, has today become the norm even in the poorest countries. The greatest achievement of the twentieth century, however, has resulted in a major challenge: how to add quality to the additional years of life.

While the growth in longevity initially occurred in developed countries, it is in the developing world that it has manifested itself in a more pronounced manner. In Brazil, the number of elderly persons (60 years of age and over) has increased from three million (in 1960) to seven million (in 1975), then 14 million (in 2000). This is an increase of 500\% in 40 years, and the total should reach 32 million by 2020 . In countries such as Belgium, however, it took a hundred years for the elderly population to double in size ${ }^{1}$.

One of the effects of this dynamic is the growing demand for health services, which can often result in a scarcity of and/or constraints on resources. The elderly use more health services and experience more frequent hospitalizations and longer bed occupancy times than other age groups. This is due to the pattern of diseases among this group, which are chronic and multiple, require constant monitoring, permanent care, continuous medication and periodic examinations ${ }^{2}$.

In health structures outside Brazil, general practitioners or family doctors are completely responsible for the treatment of $85 \%$ to $90 \%$ of their patients, without the need of specialists. Health professionals with specific training (in Nutrition, Physical Therapy or Psychology) ${ }^{3}$ are also used. In this way, the elderly have access to a much larger range of qualified professionals, who are recommended to them through their attending doctor.

In Brazil, however, there is an excess of consultations carried out by specialists, with the current model of care prioritizing the fragmentation of care. This can be clearly seen by comparisons with the model in the UK, the National Health Service (NHS), the central figure of which is the general practitioners (GP), who has a high resolutive capacity and can establish a strong bond with the patient. The NHS is offered to all citizens regardless of income or social status, in a similar manner to Brazil's SUS 4 . To be eligible for free public health care, a citizen must register with a General Practitioner (GP). The main health service units are local health care clinics composed of general practitioners and nurses. Any necessary medical care, provided it is not an extreme emergency or caused by an accident, will be performed by the doctor of that health center.

The American model, on the other hand, is based around referral to numerous medical specialists, in a model of care that is the opposite to the English. These two rich countries, with great medical traditions, therefore use different models and provide quite different results 5 .

\section{FINANCIAL PRESSURES}

The demographic transition and the improvement of Brazil's social and economic indicators, compared to previous decades, have led not only to the growth of the elderly population, but also to greater financial pressure on public and private health systems. As the number of elderly people increases, so, naturally, do the prevalence of chronic diseases and spending ${ }^{6}$.

In recent decades it has been shown that most of the public health problems that affect the population - both communicable and noncommunicable diseases - can be prevented. This is shown by the significant decrease in mortality due to coronary and cerebrovascular diseases, a reduction in the incidence of and mortality from cervical cancer, as well as a decline in the prevalence of smoking and the incidence of lung cancer in men. In summary: a major social and economic burden can be avoided through the reduction of disease?

Many still see the preventive action as a burden of procedures and additional costs. In fact it is the inverse of such thinking which, in the medium and long term, can reduce hospitalizations and other procedures of much greater cost. All the evidence indicates that biomedical health systems are likely to suffer problems of sustainability in the future. 
We live in the information age. In the field of Collective Health, epidemiological information can be translated into the capacity to predict events, enabling early diagnosis, especially in relation to chronic diseases, delaying the onset of such illnesses, improving quality of life and the effectiveness of the therapeutic approach ${ }^{5}$.

The role of the health professional in these cases is not to avoid disease (since it is already installed) or seek a cure, but to stabilize and reduce harm, aiming at maintaining quality of life ${ }^{8}$. In general terms, these are the foundations and discussion of health proposed by Caring Senior.

\section{WHAT WE KNOW BUT CHOOSE TO IGNORE}

Elderly care should be structured in a unique manner. The current provision of health services fragments care for this age group, with multiple specialist consultations, a failure to share information, widespread use of drugs, clinical and imaging exams, among other procedures that overwhelm the system, have a strong financial impact at all levels and do not generate significant benefits for health or quality of life ${ }^{1}$. One of the problems stems from the exclusive focus on disease. Even when a program based on the anticipation of illness is provided, the proposals are geared primarily towards the reduction of a certain disease, forgetting that when a chronic illness is already established in an individual the objective should not be the cure, but the stabilization of the clinical profile and constant monitoring in order to prevent or mitigate functional decline ${ }^{8}$.

Studies have shown that care must be organized in an integrated manner and must be coordinated throughout the treatment pathway, following a network-based logic from entry into the system to care at the end of life ${ }^{9}$, focusing on strategies of education, health promotion, the prevention of preventable diseases, postponement of illness, early care and rehabilitation ${ }^{10}$. The best strategy for the proper care of the elderly is the permanent monitoring of their health, varying only the levels, intensity and scenario of the intervention ${ }^{11}$.

Programs aimed at this group should be constructed based on integrated care, with the leading health professional and their team managing not the disease, but the health profile of the patient, as often the treatment of a health problem can only be conducted with the reduction or suspension of other actions ${ }^{12}$.

It is necessary to structure models that work in an integrated manner and cover the complexity of the care demanded.

\section{A FAMILIAR INNOVATION}

A health unit with broader characteristics allows the anticipation of problems through the early identification of possible symptoms, changes in mood or possible functional losses. In this way, the elderly person can be referred promptly to the attending doctor $^{13}$. Ideally, health care services should focus on providing qualified care and well-being to the elderly, ensuring their clients have a referral doctor, and that all doctors have a portfolio of clients for whom they care. This care unit should be a space with the characteristics of a social center with varied activities including medical consultations and actions aimed at integration and participation, facilitating the establishing of trust and client loyalty within the model. This "innovation" is at least 70 years old, as it has functioned in England since 1948.

Prevention is essential. The earlier the intervention is performed, the better the chances of a more positive prognosis ${ }^{3}$. The model we propose here, which we will call Caring Senior, embraces the successful British experience and offers permanent monitoring.

A phrase has been repeated for decades in medicine is that the more the healthcare professional knows about the history of their patient, the more positive the results will be. This belief is supported by the World Health Organization and all managers and professionals in the area. As logical as it is old, it still represents a modern idea of a health care model ${ }^{7}$. It is surprising, then, that we do not see it in practice on a daily basis. There should therefore be an emphasis on the integrated care of the elderly, adding conventional medical care to the development of supervised educational and leisure activities. The purpose is to maintain, for as long as possible, a good quality of life. 
To say that monitoring health and anticipating predictable illnesses is a "different and innovative" way of caring calls into question the efficiency of healthcare managers, as such an idea was established at the beginning of the last century, and it is absurd to consider it new.

The main risk factor of most of the chronic diseases that affect the elderly individual is age itself. Aging without chronic illnesses is the exception rather than the rule. Thus, the focus of any contemporary policy should be to promote healthy aging, by maintaining and improving - where possible -the functional capacity of the elderly, the prevention of diseases, recovery of the health of those who have become sick (or stabilization of illnesses) and the rehabilitation of those who have had their functional capacity restricted. Actions such as these, however, remain uncommon. The greatest investment continues to be in traditional care, with emphasis on the hospital structure ${ }^{14}$.

We must understand this dichotomy better, and ask why it is so difficult to implement prevention programs, even when they are widely accepted in theory.

\section{OUR PROPOSAL}

To put into practice what we advocate, the model of care for the elderly in Brazil must be urgently redesigned $^{15}$. The Caring Senior care model was designed with these basic assumptions in mind, and is characterized by a focus on low intensity instances of care, through the constant monitoring of the elderly and light, but intensive care, as it is known that more than $85 \%$ of such clients do not require more complex care, provided that they are properly monitored.

Other actions of health will be the responsibility of another structure which is responsible for dealing with segments such as the emergency unit, the hospital, clinical and imaging exams and medical specialists. Caring Senior will involve some specialist doctors and will also accompany its clients in highintensity instances of care - but as a support, not as a central element of care, as we will see below.
Caring Senior is based on certain principles. The first is the role of the doctor, who will be responsible for a portfolio of clients. A nurse will also be available, performing an effective role in providing care to this clientele and ensuring better quality of care. The clinical unit will have several such pairs of general practitioners and nurses, while a 40-hour workweek will allow for portfolios that can cover from 800 to a maximum of 1,000 clients. This will guarantee that professionals have the time to attend each client properly, ensuring appointments at least four times a year, and accompanying them in other instances of care, if necessary.

A full Caring Senior unit, for example, will have five pairs of doctors and nurses who are responsible for around 4,000 to 5,000 patients. The site must also include health professionals trained to provide care within the philosophy of the program, prioritizing promotion and prevention. These will include psychologists, nutritionists, physiotherapists and physical educators, who will attend cases selected by doctors. These professionals will lead group activities and lectures and provide guidance on relevant topics.

In addition to a full Caring Senior unit, each region (depending of course on demand) will have two or three minimum capacity units, featuring only a doctor/nurse pairing, with all support service provided in the full unit.

To those concerned about the possible high costs of maintaining this structure, it is worth noting that health professionals cost much less than a day's stay in an Intensive Care Unit or a hospital. To provide good care, to avoid the exaggerated use of specialist doctors and unnecessary hospitalizations, it is essential to maintain a good quality reception structure.

\section{CENTRAL POINTS OF THE MODEL}

An adult client over 49 years of age with one or more chronic diseases will not be cured. The physician's duty is to stabilize, monitor, and ease the pain caused by the disease, which will remain with the patient for the rest of their lives. The role of the Caring Senior general practitioner will be to maintain the functional capacity of clients so that they can a full and healthy life. 
The benefit of Caring Senior will be the reduction of specialist doctors and subsequent lower numbers of exams and drugs, as client loyalty will prevent them from resorting to emergency units and greatly reduce hospitalization periods.

It should be remembered that Caring Senior involves low-intensity instances of care, and is largely composed of care provided by well-trained health professionals concerned with preserving the quality of life and social participation of the elderly client. Instances considered high-intensity are those which are expensive and which involve the hospital and other long stay units. All effort must be taken to rehabilitate the elderly and return them to lowintensity instances of care.

\section{TECHNOLOGY AS A DIFFERENCE MAKER}

A high quality, lightweight technology information system will provide fundamental support for the doctor/nurse pairing and facilitate client loyalty. Without the use of technology, the Caring Senior project is not feasible, and so participants must be able to use the system to its maximum potential.

The faces of clients for example, could be recognized when they go through the door of the clinic, instantly opening their medical records on the receptionist's desk. The receptionist can then address the client by name, ask about their family, and check the list of medications they are taking. These actions are extremely simple, but they add enormous trust to the relationship, making the client feel protected and welcomed from the first moment.

Registering the care pathways of the patient is a unique feature of this model. A high-quality information system that is broad in scope can document not only the clinical evolution of the elderly person, but also their participation in individual or collective prevention actions, as well as the support of the nurse and the telephone calls made, all of which must be resolutive, with trained and qualified personnel.

The telephone contact between patients and professionals should involve the sharing of all information with the team, to enable a comprehensive assessment of the individual. The information system, which begins with the registration of the client, is one of the pillars of the program. Through it, the entire care pathway can be monitored at each level, verifying the effectiveness of the actions and contributing to decision-making and follow-up. It is a unique electronic record, both longitudinal and involving a range of professionals, which accompanies clients from reception onwards. This medical record differs from existing registries as it includes a record of their life history and health events.

The creation of a mobile app with individualized information and reminders of consultations and prescribed actions is also envisaged. This can, among other actions, ask the client to take a photo of their breakfast and send it to the nutritionist, who will observe if the meal is balanced and if there are adequate amounts of fiber, for example.

Caring Senior will focus on maintaining the clientele within its units, avoiding the use of specialists. Five areas of medical specialties related to our model, who can assist the general practitioner, will be required. The choice of such specialties is based on demand and high prevalence, as well as featuring areas where annual preventive control examinations can be carried out and registered. They are: cardiology, gynecology, urology-proctology, dermatology and ophthalmology.

Consultation with the specialties listed will only be possible at the request of the client's general practitioner. If the client requires the care of one specialist, Caring Senior will not therefore include the other specialties. The same reasoning applies to hospitalization. Doctors and nurses will be responsible for contacting the hospital doctor, armed with knowledge of the case and, preferably, acting to ensure the best care and the shortest hospitalization time, as well as being able, if necessary, to suggest a medical specialist.

\section{REMUNERATION}

Another key element of Caring Senior is the form of payment of physicians, the Accountable Care Organizations (ACO) system, which encourages healthcare professionals to organize themselves as 
a group, managing the quality of services provided, being responsible for cost management and the distribution of bonuses ${ }^{16}$.

There are two key points: the provision of services of excellence at a lower cost and a model of remuneration based on added value. The segmented and non-integrated health that is offered to patients today is largely due to the service remuneration model, in which the incentive is production, rather than quality ${ }^{17}$. In other words, there is no benefit in seeking new forms of care or new payment models if the transfer of part of the responsibilities, risks and benefits of providers is not associated with the results achieved through the care offered.

The challenge is to make this new care model acceptable to the client, since trust (which will lead to loyalty) is an indispensable factor if the process is to function as planned. One cannot, after all, ask a person to trust something they do not know.

It benefits no one to declare that Caring Senior is the best model if it is not applied by Brazilian supplementary health services. Society needs to be made fully aware of the proposal if it is to convince itself of its benefits ${ }^{2}$. Otherwise, healthcare will continue to opt for the "siren song" of excess and consumption, which burden the system, generate higher costs, and render long-term care unfeasible.

\section{CONCLUSION}

The socioeconomic transformations of recent decades and the consequent changes in the lifestyles of individuals in contemporary societies - with changes in eating habits, increased sedentarism and stress, plus the increasing life expectancy of the population - have contributed to a higher incidence of chronic diseases, which today constitutes a serious public health problem.

The current provision of health services fragments care for the elderly. It overloads the system, causes a strong financial impact at all levels and does not generate significant benefits for quality of life. It is therefore imperative that a new model is adopted. If we know the population is older, that diseases are chronic and multiple, that the costs of care increase, that the models of care are from a time of acute diseases and that a knowledge of epidemiology can inform us about risk factors, why do we continue to offer an outdated and ineffective product? Especially if we have all the information required to implement an assistance-based care model in which everyone benefits?

It is necessary to rethink and redesign the care to the elderly, turning the focus to the individual and their particularities. This will bring benefits not only to this part of the population, but also quality and sustainability to the entire Brazilian health system.

It is possible to reorient the healthcare of the elderly population and to build an organization within this sector that provides better welfare and economic-financial results. To achieve this, everyone involved must realize they are responsible for the changes required and allow themselves to innovate - which, in many situations, means recovering the simpler care and values that have been lost within our health system.

\section{REFERENCE}

1. Veras RP, Oliveira MR. Linha de cuidado para o idoso: detalhando o modelo. Rev Bras Geriatr Gerontol. 2016;19(6):887-905.

2. Szwarcwald CL, Damacena GN, Souza Júnior PRB, Almeida WS, Malta DC. Percepção da população brasileira sobre a assistência prestada pelo médico. Cienc Saúde Colet. 2016;21(2):339-50.
3. Silva AMM, Mambrini JVM, Peixoto SV, Malta DC, Lima-Costa MF. Uso de serviços de saúde por idosos brasileiros com e sem limitação funcional. Rev Saúde Pública [Internet]. 2017 [acesso em 01 jun. 2018];51(Suppl 1):1-10. Epub 01 jun. 2017. Disponível em: http://www.scielo.br/scielo.php?script $=$ sci_ arttext\&pid=S0034-89102017000200302\&lng=pt 
4. Box G. Understanding and responding to demand in English general practice. Br J Gen Pract. 2016;66(650):456-7.

5. Oliveira MR, Silveira DP, Neves R, Veras R, Estrella $\mathrm{K}$, Assalim VM, et al. Idoso na saúde suplementar: uma urgência para a saúde da sociedade e para a sustentabilidade do setor. Rio de Janeiro: ANS; 2016.

6. Veras RP, Estevam AA. Modelo de atenção à saúde do idoso: a ênfase sobre o primeiro nível de atenção. In: Lozer AC, Godoy CVC, Coelho KSC, Leles FAG, organizadores. Conhecimento técnico-científico para qualificação da saúde suplementar. Brasília, DF: OPAS; 2015. p. 73-84.

7. Carvalho VKS, Marques CP, Silva EN. A contribuição do Programa Mais Médicos: análise a partir das recomendações da OMS para provimento de médicos. Ciênc Saúde Colet [Internet]. 2016 [acesso em 01 jun. 2018];21(9):2773-84. Disponível: http://www.scielo.br/scielo.php?script=sci_ arttext\&pid=S1413-81232016000902773\&lng=en

8. Veras RP, Oliveira M. "Envelhecer no Brasil: a construção de um modelo de cuidado". Ciênc Saúde Colet. 2018;23(6):1929-36.

9. Mendes EV. As redes de atenção à saúde. Brasília, DF: OPAS; 2011.

10. Oliveira MR, Veras RP, Cordeiro HA, Pasinato MT. A mudança de modelo assistencial de cuidado ao idoso na Saúde Suplementar: identificação de seus pontos-chave e obstáculos para implementação. Physis. 2016;26(4):1383-94.
11. Veras RP, Caldas CP, Motta LB, Lima KC, Siqueira RC, Rodrigues RTSV, et al. Integração e continuidade do cuidado em modelos de rede de atenção à saúde para idosos frágeis. Rev Saúde Pública. 2014;48(2):357-65.

12. Oliveira M, Veras RP. "Um modelo eficiente no cuidado à pessoa idosa”. Correio Brasiliense. 27 ago. 2015: Seção Opinião. p. 13.

13. Oliveira M, Veras RP, Cordeiro H. A Saúde Suplementar e o envelhecimento após 19 anos de regulação: onde estamos? Rev Bras Geriatr Gerontol [Internet]. 2017 [acesso em 17 maio 2018];20(5):624-33. Disponível em: http://www. scielo.br/scielo.php?script $=$ sci_arttext\&pid=S1809$98232017000500624 \& \operatorname{lng}=$ pt\&nrm $=$ iso

14. da Silveira DP, Araújo DV, Gomes GHG, Lima KC, Estrella K, Oliveira M, et al. Idoso na saúde suplementar: uma urgência para a saúde da sociedade e sustentabilidade do setor. Rio de Janeiro: ANS; 2016.

15. Moraes EM. Atenção à saúde do idoso: aspectos conceituais. Brasília, DF: OPAS; 2012.

16. Médici A, Abicalaffe C, Tavares L. Pagamento por Performance [Internet]. [Sem Local]: Empreender Saúde; 2015 [acesso em 17 maio 2018]. Disponível em: https://www.researchgate. net/publication/281642162_Pagamento_por_ Performance_em_Saude\#pf3

17. Abicalaffe CL. Pagamento por performance: o desafio de avaliar o desempenho na área da saúde. J Bras Econ Saúde. 2011;3(1):179-85. 